\title{
Unwrap Them First: Operando Potential- induced Activation Is Required when Using PVP-Capped Ag Nanocubes as Catalysts of $\mathrm{CO}_{2}$ Electroreduction
}

\author{
María de Jesús Gálvez-Vázqueza , Heng Xub , Pavel Moreno-García ${ }^{a}$, Yuhui Houa , Huifang Hua, \\ Benjamin J. Wiley ${ }^{\mathrm{b}}$, Soma Vesztergom ${ }^{\star c}$, and Peter Broekmann ${ }^{\star a}$
}

\begin{abstract}
Metallic nanoparticles of different shape can be used as efficient electrocatalysts for many technologically and environmentally relevant processes, like the electroreduction of $\mathrm{CO}_{2}$. Intense research is thus targeted at finding the morphology of nanosized features that best suits catalytic needs. In order to control the shape and size distribution of the designed nanoobjects, and to prevent their aggregation, synthesis routes often rely on the use of organic capping agents (surfactants). It is known, however, that these agents tend to remain adsorbed on the surface of the synthesized nanoparticles and may significantly impair their catalytic performance, both in terms of overall yield and of product selectivity. It thus became a standard procedure to apply certain methods (e.g. involving UV-ozone or plasma treatments) for the removal of capping agents from the surface of nanoparticles, before they are used as catalysts. Proper design of the operating procedure of the electrocatalysis process may, however, render such cleaning steps unnecessary. In this paper we use poly-vinylpyrrolidone (PVP) capped Ag nanocubes to demonstrate a mere electrochemical, operando activation method. The proposed method is based on an observed hysteresis of the catalytic yield of $\mathrm{CO}$ (the desired product of $\mathrm{CO}_{2}$ electroreduction) as a function of the applied potential. When as-synthesized nanocubes were directly used for $\mathrm{CO}_{2}$ electroreduction, the $\mathrm{CO}$ yield was rather low at moderate overpotentials. However, following a potential excursion to more negative potentials, most of the (blocking) PVP was irreversibly removed from the catalyst surface, allowing a significantly higher catalytic yield even under less harsh operating conditions. The described hysteresis of the product distribution is shown to be of transient nature, and following operando activation by a single 'break-in' cycle, a truly efficient catalyst was obtained that retained its stability during long hours of operation.
\end{abstract}

Keywords: Catalyst activation $\cdot \mathrm{CO}_{2}$ reduction - Electrocatalysis $\cdot$ Nanoparticles $\cdot$ Polyvinylpyrrolidone (PVP)

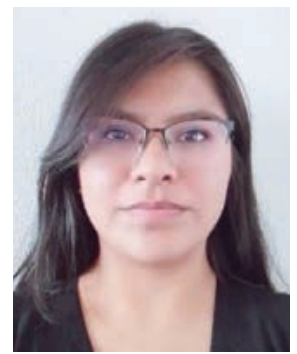

María de Jesús Gálvez-Vázquez studied chemistry and received her MSc specialization in materials science at the Benemérita Universidad Autónoma de Puebla in Mexico. In 2017 she started her $\mathrm{PhD}$ project in the group of Prof. Dr. Peter Broekmann at the University of Bern. Her main focus is the study of different catalyst materials applied for the electrochemical reduction of carbon dioxide under controlled mass transport conditions.

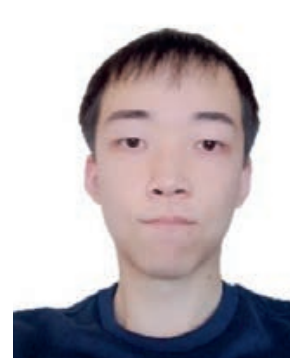

Heng $\boldsymbol{X u}$ is a $\mathrm{PhD}$ student in the Department of Chemistry at Duke University. He received his BSc in chemistry from Jilin University in 2018 and then joined Prof. Dr. Benjamin J. Wiley's group in the same year. His research interests include the shape-controlled synthesis of metal nanocrystals and understanding of the anisotropic growth of metal nanocrystals with electrochemistry.

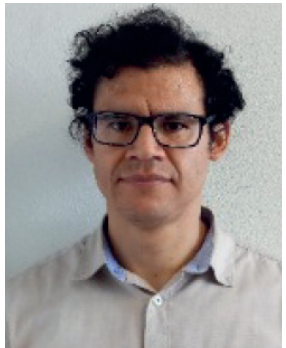

Dr. Pavel Moreno-García obtained a $\mathrm{PhD}$ in chemistry and molecular science at the University of Bern in 2013, under supervision of Prof. Dr. Thomas Wandlowski. At that time, his work was devoted to the study of electronic transport through nanoobjects at electrified interfaces by in situ STM. In 2013, he joined the group of Prof. Dr. Peter Broekmann, where he is involved in electrocatalysis research on the direct electrochemical conversion of carbon dioxide to more valuable products, instrumental development, and studies using laser ablation/ ionization mass spectrometry.

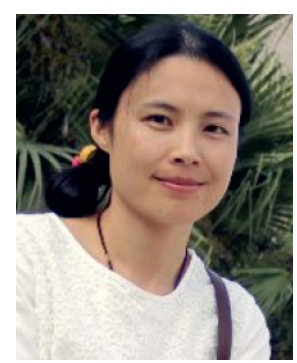

Dr. Yuhui Hou received her PhD in physical chemistry from Xiamen University, China in 2015. Before joining Prof. Dr. Peter Broekmann's group at the University of Bern, she worked as a post-doctoral fellow in Hokkaido University (Japan), where she mainly focused on methane conversion. Her current research interest is to develop 
electrocatalysts via colloidal synthesis for electrochemical $\mathrm{CO}_{2}$ reduction. She is also interested in investigating catalyst degradation under electrochemical $\mathrm{CO}_{2}$ reduction conditions by identicallocation scanning electron microscopy.

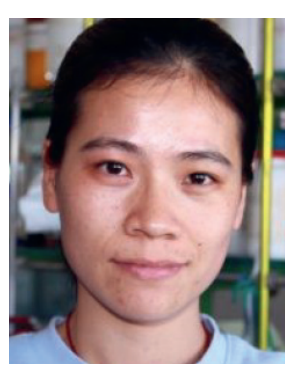

Huifang $\mathbf{H u}$ obtained her MSc in materials science and engineering from Fuzhou University (China). After a short experience in technical college, she joined the Interfacial Electrochemistry Group of Prof. Dr. Peter Broekmann as a PhD student in 2019. Her PhD project focuses on the electrochemical conversion of $\mathrm{CO}_{2}$ into valueadded products.

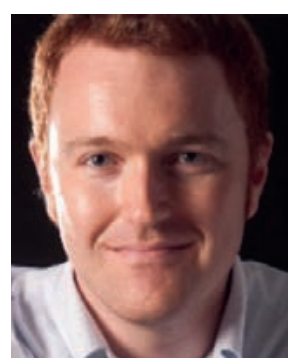

Prof. Dr. Benjamin J. Wiley is a professor in the Department of Chemistry at Duke University. He received his BSc in chemical engineering from the University of Minnesota in 2003, and his $\mathrm{PhD}$ in chemical engineering from the University of Washington, Seattle in 2007. Prof. Dr. Wiley is the recipient of the Beilby Medal from the Royal Society of Chemistry and has been recognized as a Highly Cited Researcher by Thomson Reuters in 2014 and 2018. His current research focuses on understanding the processes that drive anisotropic growth of nanostructures and understanding the structure-property relationship of nanostructures and for applications in electronics, medicine, and electrochemistry.

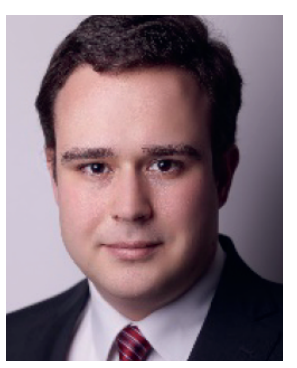

Dr. Soma Vesztergom obtained his MSc (2010) and PhD (2014) degrees in chemistry, working with Prof. Dr. Gyốzố G. Láng at Eötvös Loránd University, Hungary. He was a post-doctoral researcher in Prof. Dr. Peter Broekmann's group at the University of Bern for a year (2014) and is a regular collaborator of this group since then. His research primarily focuses on instrumental developments in electrochemistry and on the modelling of electrocatalytic processes. Currently, he is an assistant professor at Eötvös Loránd University in Budapest.

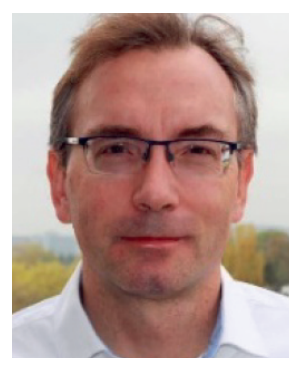

Prof. Dr. Peter Broekmann obtained his MSc in chemistry (1998) and a PhD (2000) from the University of Bonn. After a postdoctoral stay at the University of Twente (The Netherlands) in 2001, he became project leader at the Institute of Physical Chemistry in Bonn. Since 2008 he holds a lecturer position for electrochemistry at the University of Bern. His research focuses on metal deposition processes for semiconductor and electrocatalysis applications.

\section{Introduction}

As a result of the ever-increasing consumption of fossil fuels, gigatons of $\mathrm{CO}_{2}$ are released to the atmosphere every year, expediting global warming. ${ }^{[1]} \mathrm{A}$ possible way of mitigating the effects of rising $\mathrm{CO}_{2}$ concentrations in the atmosphere is to reduce it electrochemically. This approach does not only allow $\mathrm{CO}_{2}$ to be regarded as a valuable raw material instead of an environmentally dangerous waste, but it may also provide a solution for the storage of excess renewable (hydro-, solar or wind) energy. ${ }^{[1]}$ It is probably for this reason that the topic of electrochemical $\mathrm{CO}_{2}$ reduction - an otherwise more than 150 years old idea ${ }^{[2]}$ - has recently become the forefront of electrochemical research. ${ }^{[3]}$ Today, a tremendous amount of research is invested in the design of new electrocatalyst materials for $\mathrm{CO}_{2}$ electroreduction, and researchers seem to agree that apart from their chemical composition it is the nanoscale structure of electrocatalysts that mostly affect their performance. ${ }^{[4,5]}$

In order to create nanosized catalyst particles with a welldefined size and structure distribution, and to avoid the agglomeration of such particles, the synthesis route of colloidal catalyst nanoparticles (NPs) very often involves the use of surfactants (capping agents). When the aim is to synthesize metallic (e.g. Ag[6,7]) NPs, a very often used agent is poly-(vinylpyrrolidone), PVP. PVP owes its popularity to a four-fold synergistic effect, i.e. depending on the conditions of synthesis, it may act as a stabilizer, a shape control, a dispersant and/or a reducing agent. ${ }^{\left[{ }^{[8}\right.}$ Although PVP can be used for the design of a variety of Ag nanostructures (such as nanocubes ${ }^{[6,9]}$ or nanowires $\left.{ }^{[10]}\right)$, the application of such agents has one significant drawback. That is, surfactants used for the synthesis tend to remain adsorbed on the surface of the nanoparticles, hindering or even impairing their catalytic activity.

As a result, capping agent removal steps must be applied before the NPs can effectively be used as catalysts in a $\mathrm{CO}_{2}$ electroreduction process. Removal steps often imply the use of additional solvents, ${ }^{[11]}$ or they rely on high temperature plasma ${ }^{[12]}$ or UV-ozone treatments. ${ }^{[13]}$ These require precise optimization in order to remove most of the capping agents while keeping effects detrimental to the catalyst structure at a minimum. Of course, in order to keep the catalyst particles as intact as possible, evading any forms of thermal treatments would be highly desirable, and in this respect the application of electrochemical activation methods seem to provide a viable alternative. That the application of harsh reductive potentials in an electrochemical cell can successfully activate a catalyst (that may afterwards be used more effectively, even under milder conditions) was recently shown by our group for $\mathrm{Ag}$ nanowires, ${ }^{[10]}$ and by the group of Buonsanti ${ }^{[14]}$ for $\mathrm{Cu}$ nanocrystal catalysts.

In this short communication we aim to investigate this effect further, and show that by applying PVP-capped (untreated) $\mathrm{Ag}$ nanocubes for the electroreduction of $\mathrm{CO}_{2}$, a positive hysteresis effect can be observed when determining the catalytic selectivity towards $\mathrm{CO}$ formation as a function of the applied (cathodic) potential. Based on these findings we infer that instead of using thermal methods, surface-pinned capping agents could also be removed and metallic NP catalysts can be activated operando, by the application of a 'break-in' cycle in the electrolysis cell.

Effective 'break in', in the case of PVP-capped Ag nanocubes (Ag NCs) applied for the electroreduction of $\mathrm{CO}_{2}$, requires the setting of harsh cathodic potentials. Under such conditions, although the $\mathrm{CO}: \mathrm{H}_{2}$ yield ratio is far from ideal, most of the capping agents are irreversibly desorbed from the surface of the NCs. While during the time of 'break-in', some catalyst degradation does occur, at the end we obtain a catalyst that works better even under normal (not so harsh) operating conditions. Improvement can be seen both in the achievable current and in the higher selectivity for $\mathrm{CO}$ production.

\section{Experimental}

\subsection{Synthesis of Ag NCs}

Ag NCs were synthesized using a previously reported method with minor modification. ${ }^{[6]} 5 \mathrm{~cm}^{3}$ of ethylene glycol (J. T. Baker) was added to a $250 \mathrm{~cm}^{3}$ two-neck flask preheated to $160{ }^{\circ} \mathrm{C}$. A light $\mathrm{N}_{2}$ flow was introduced just above the ethylene glycol for the first $10 \mathrm{~min}$, followed by heating the solvent for another 50 min. Next, $3 \mathrm{~cm}^{3}$ ethylene glycol solution of $\mathrm{AgNO}_{3}(94 \mathrm{mmol}$ 
$\mathrm{dm}^{-3}$ ) and $3 \mathrm{~cm}^{3}$ ethylene glycol solution containing polyvinylpyrrolidone $\left(M_{\mathrm{w}}=55000 \mathrm{~g} \mathrm{~mol}^{-1}, 144 \mathrm{mmol} \mathrm{dm}^{-3}\right)$ and $\mathrm{NaCl}(0.22$ mmol dm${ }^{-3}$ ) were simultaneously injected into the flask at a rate of $45 \mathrm{~cm}^{3} \mathrm{~h}^{-1}$, with the solution observed to turn yellow during this process. Under continuous stirring at $160{ }^{\circ} \mathrm{C}$, the solution exhibited a color transition series from yellow to clear yellow, brown, greenish, and finally ochre and opaque. The whole process required 16 to $24 \mathrm{~h}$ for completion. After the solution had turned opaque, the reaction was quenched by adding $22 \mathrm{~cm}^{3}$ acetone to the hot solution, followed by cooling in an ice-water bath. To purify the NCs, the solution was first centrifuged at $2000 \mathrm{~g}$ for $30 \mathrm{~min}$, then the precipitate was dispersed and centrifuged, three times, in $10 \mathrm{~cm}^{3}$ of deionized water at $9000 \mathrm{~g}$ for $10 \mathrm{~min}$ per run. ${ }^{[15]}$

\subsection{Preparation of Ag NCs catalyst ink}

For the preparation of the carbon-supported Ag NCs ink, $1.5 \mathrm{mg}$ of the Ag NCs and $0.26 \mathrm{mg}$ of carbon black (Vulcan XC 72R, Cabot) were separately dispersed in $10 \mathrm{~cm}^{3}$ of isopropanol (VLSI Selectipur, BASF) by $1 \mathrm{~h}$ sonication. Both suspensions were intermixed, sonicated for $1 \mathrm{~h}$ and dried using a rotary evaporator. The obtained carbon-supported Ag NCs were then re-dispersed in $1 \mathrm{~cm}^{3}$ of isopropanol containing $50 \mu \mathrm{l}$ of Nafion (5 wt. $\%, 15-20 \%$ water, Sigma-Aldrich). The resulting suspension was subjected to sonication for $1 \mathrm{~h}$, yielding a homogeneous catalyst ink $(85 \% \mathrm{Ag}$ NCs and $15 \%$ carbon black).

\subsection{Preparation of the Gas Diffusion Electrodes}

Ag NCs containing gas diffusion electrodes (Ag NC GDEs) for all electrochemical and characterization experiments were prepared as follows: a $0.8 \mathrm{~cm} \times 3 \mathrm{~cm}$ carbon paper (Sigracet 39 $\mathrm{BC}$, Fuel Cell Store) was cut and placed over a nylon membrane filter (pore size $0.22 \mu \mathrm{m}$, Fischerbrand) on top of the funnel of a vacuum filtrating system. The GDE was then covered by a rectangular mask, leaving $0.2 \mathrm{~cm}^{2}$ uncovered and $141.5 \mu \mathrm{l}$ of the carbon supported Ag NCs ink was drop-cast on top of it. The resulting Ag NC GDEs were dried at ambient conditions for at least $30 \mathrm{~min}$ and then their backside and edges were masked with Teflon tape, to leave only the Ag NCs ink-modified surface uncovered $\left(0.2 \mathrm{~cm}^{2}\right)$. Analysis by inductively coupled plasma-mass spectrometry (ICP-MS) of the freshly prepared samples was used to determine the catalyst mass loading, which amounted to $\sim 71 \mu \mathrm{g} \mathrm{cm}^{-2} \mathrm{Ag}$.

\subsection{Electrochemical Measurements and Product Analysis}

Electrochemical experiments were performed using a PGSTAT128N potentiostat/galvanostat (Metrohm Autolab) and a custom-made, airtight H-type cell with a Nafion membrane (Nafion 117, Sigma Aldrich) separating the cathode and anode compartments. The three-electrode arrangement consisted of the Ag-NC-GDE working, a Pt foil $(1 \mathrm{~cm} \times 1 \mathrm{~cm})$ counter and a single junction (Pine Research) $\mathrm{Ag}|\mathrm{AgCl}| \mathrm{KCl}$ (sat.) reference electrode. Reported current densities were obtained by normalizing the current to the geometric surface area of the working electrode, $0.2 \mathrm{~cm}^{2}$. Prior to the electrolysis experiments, both cell compartments were filled with $32 \mathrm{~cm}^{3}$ of either $0.5 \mathrm{~mol} \mathrm{dm} \mathrm{dm}^{-3}$ or $2 \mathrm{~mol} \mathrm{dm}^{-3} \mathrm{KHCO}_{3}$ solution (ACS grade, Sigma-Aldrich) and then saturated by $\mathrm{CO}_{2}$ gas $(99.999 \%$, Carbagas, Switzerland) for at least $30 \mathrm{~min}$. For the sake of comparability, electrode potentials in the paper are referred to the reversible hydrogen electrode (RHE), calculated as:

$$
E_{v s . \mathrm{RHE}}=E_{v s . \mathrm{Ag} \mid \mathrm{AgCl}}+210 \mathrm{mV}+59 \mathrm{mV} \cdot p \mathrm{H}
$$

For all potentiostatic experiments, the measured electrode potential was $I R$-corrected post-experimentally, for which the solu- tion resistance was determined impedimetrically at the beginning of electrolysis. The $p \mathrm{H}$ values of the $\mathrm{CO}_{2}$-saturated $0.5 \mathrm{~mol} \mathrm{dm}^{-3}$ and $2 \mathrm{~mol} \mathrm{dm}^{-3} \mathrm{KHCO}_{3}$ solutions were 7.4 and 7.9, respectively. Electrolyses were run for $60 \mathrm{~min}$ and online gas chromatography was applied (every $20 \mathrm{~min}$ ) to quantify the formed products.

Gaseous products generated in the cell were detected by connecting the purging gas outlet to a GC analyzer (SRI Instruments Multigas Analyzer). The continuous flow of the carrier $\mathrm{CO}_{2}$ gas through the electrolysis cell carried volatile reaction products from the head-space into the sampling loops of the gas chromatograph. The partial current $I_{i}$, corresponding to the formation of a gaseous product $i$, can be calculated ${ }^{[16]}$ as

$$
I_{i}=x_{i} n_{i} F v_{\mathrm{m}}
$$

where $x_{i}$ denotes the mole fraction of the products, determined by GC using an independent calibration standard gas (Carbagas); $n_{i}$ is the number of electrons involved in the reduction reaction to form a particular product ( $n=2$ for both $\mathrm{CO}$ and $\mathrm{H}_{2}$ formation); $\mathrm{F}$ $=96485.3 \mathrm{C} \mathrm{mol}^{-1}$ is Faraday's constant; and $v_{\mathrm{m}}$ is the molar $\mathrm{CO}_{2}$ gas flow rate measured by a universal flowmeter (7000 GC flowmeter, Ellutia) at the exit of the electrochemical cell. The Faradaic efficiency (FE) of a given reaction product can be determined by dividing the respective partial current, determined from Eqn. (2), by the total current measured electrochemically. A thermal conductivity detector (TCD, for the detection of $\mathrm{H}_{2}$ ) and a flame ionization detector (FID, for the detection of $\mathrm{CO}$ ) were equipped to our gas chromatograph.

The electrolyte was analyzed after the electrolysis experiment to quantify the amount of formate produced by means of ion exchange chromatography (Metrohm Ltd., Switzerland). This chromatograph was coupled to an L-7100 pump, a separation and an ion exclusion column (Metrosep A Supp 7-250) and a conductivity detector.

\subsection{Scanning Electron Microscopy (SEM) and Energy- dispersive X-ray Spectroscopy (EDX) Characterization}

The morphological characterization of the prepared Ag NC GDEs by SEM imaging experiments was performed before (for the as-prepared electrodes) and after electrochemical treatment. Analysis was conducted using a Zeiss Gemini 450 SEM equipped with an InLens secondary electron and a back-scattered electron detector. An accelerating voltage of $5 \mathrm{kV}$ and a beam current of $200 \mathrm{pA}$ were applied at a working distance of $4.5 \mathrm{~mm}$. The AZtec 4.2 software (Oxford Instruments) was used to acquire EDX surface mappings of selected Ag NC GDEs. An acceleration voltage of $10 \mathrm{kV}$ and a beam current of $1.2 \mathrm{nA}$ were applied at a working distance of $8.5 \mathrm{~mm}$.

\subsection{Determination of Catalyst Loading by Inductively Coupled Plasma-Mass Spectrometry (ICP-MS)}

Freshly prepared Ag NC GDEs were immersed in $3 \mathrm{~cm}^{3}$ of concentrated $\mathrm{HNO}_{3}$ (BASF) to dissolve the $\mathrm{Ag}$ NCs embedded on their surfaces for $24 \mathrm{~h}$. The resulting solutions were diluted with $3 \% \mathrm{HNO}_{3}$ solution by a factor of 500 and were then fed into a NExION 2000 ICP-MS instrument (Perkin Elmer) to obtain the Ag mass loading of the electrodes.

\section{Results and Discussion}

A peculiar hysteresis effect (Fig. 1) was observed when conducting electrolysis experiments coupled to chromatographic product detection using PVP-capped $\mathrm{Ag} \mathrm{NCs}$ in a $\mathrm{CO}_{2}$ saturated, $2.0 \mathrm{~mol} \mathrm{dm}^{-3} \mathrm{KHCO}_{3}$ solution. Here we carried out potentiostatic electrolyses, all lasting for one hour, and recorded a relatively stationary current that was later averaged and 
compared to the amounts of $\mathrm{CO}$ and $\mathrm{H}_{2}$, determined by gas chromatography. It is important to note that the determined total amounts of $\mathrm{CO}$ and $\mathrm{H}_{2}$ did not account for a $100 \%$ of Faradaic efficiency, and some $5 \%$ of formate $\left(\mathrm{HCOO}^{-}\right)$was found in the solution by post-electrolysis liquid chromatography analysis after each electrolysis, practically independently from the applied potential.

The first electrolysis experiment was carried out at an applied potential of $-0.75 \mathrm{~V} v s$. RHE, where the Faradaic efficiency of CO production was relatively low, $55 \%$. By gradually stepping the potential in the cathodic direction, the $\mathrm{FE}$ of $\mathrm{CO}$ production first increased, reaching a maximum of $\sim 82 \%$ at around $-0.9 \mathrm{~V}$, as shown in Fig. 1(a). At potentials even more negative, $\mathrm{CO}_{2}$ reduction ( $\mathrm{CO}$ production) became disfavored compared to the competing hydrogen evolution reaction (HER).

In our experiments, $-1.1 \mathrm{~V}$ was the most extreme potential reached, following which we began to gradually apply lower voltages. As shown in Fig. 1(a), after a first excursion to $-1.1 \mathrm{~V}$, the measured $\mathrm{FE}$ of $\mathrm{CO}$ production remained higher even at potentials just mildly cathodic, and the FE of $\mathrm{CO}$ production did not drop below $70 \%$ at potentials as positive as $-0.6 \mathrm{~V} v s$. RHE.

It is interesting to note in Fig. 1(b), showing plots of partial current densities of $\mathrm{CO}$ and $\mathrm{H}_{2}$ formation as a function of potential, that the partial current of HER follows - within range of error - the same track during the negative and the positive going scans of the potential excursion. For CO, however, a significant enhancement of currents can be observed during the latter, positive going scan, which allows us to conclude that the first potential excursion to extremely negative potentials indeed served as a 'break-in' of the catalyst. Although it is obvious that $-1.1 \mathrm{~V}$, in the current system, is not an ideal operating potential, it seems that applying this value for a short time allows the catalyst to be operated, later on, at milder potentials, where it can then still produce $\mathrm{CO}$ with a good yield.

The described activation method has its origins in the potential-induced removal of PVP from the surface of the Ag NCs, occurring at negative potentials that can overcome the
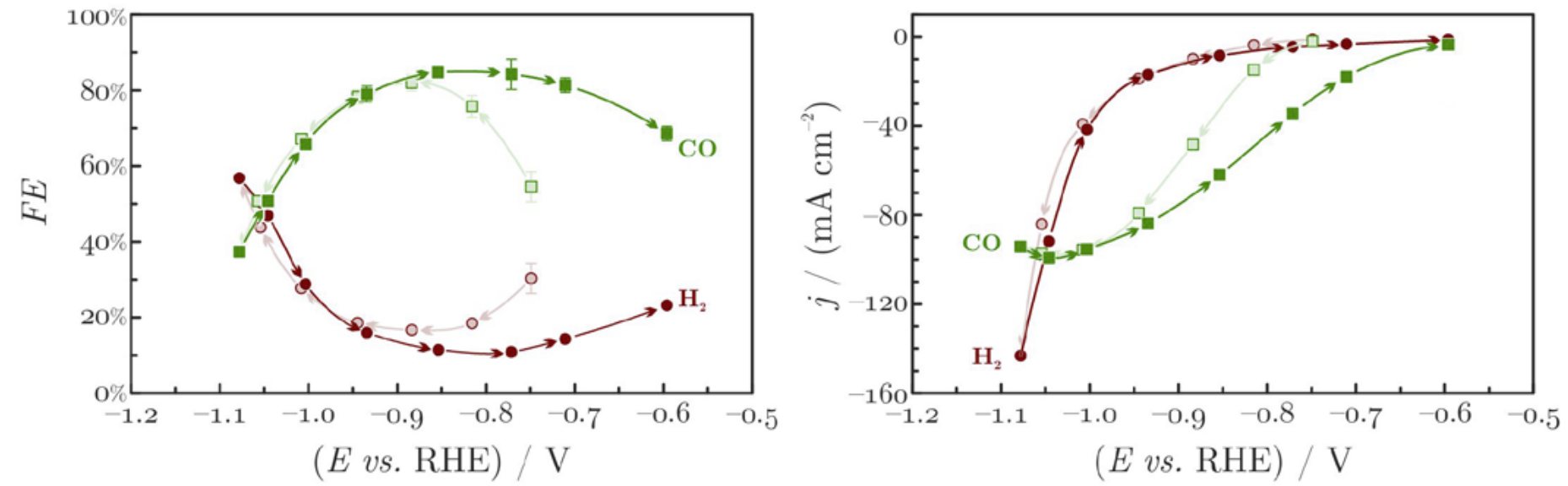

Fig. 1. Potentiostatic electrolyses were carried out using PVP-coated Ag NCs dropcast on a GDE, used as electrocatalysts of $\mathrm{CO}_{2}$-reduction in a $\mathrm{CO}_{2}$-saturated $2.0 \mathrm{~mol} \mathrm{dm}^{-3} \mathrm{KHCO}_{3}$ solution. Faradaic efficiencies (a) and partial current densities (b) of $\mathrm{CO}$ (green) and $\mathrm{H}_{2}$ (red) are shown as a function of the IR-drop corrected electrode potential. Data (dots) were recorded by gas chromatography; trends (curves) were created by spline interpolation. Arrows show the direction of the potential excursion.
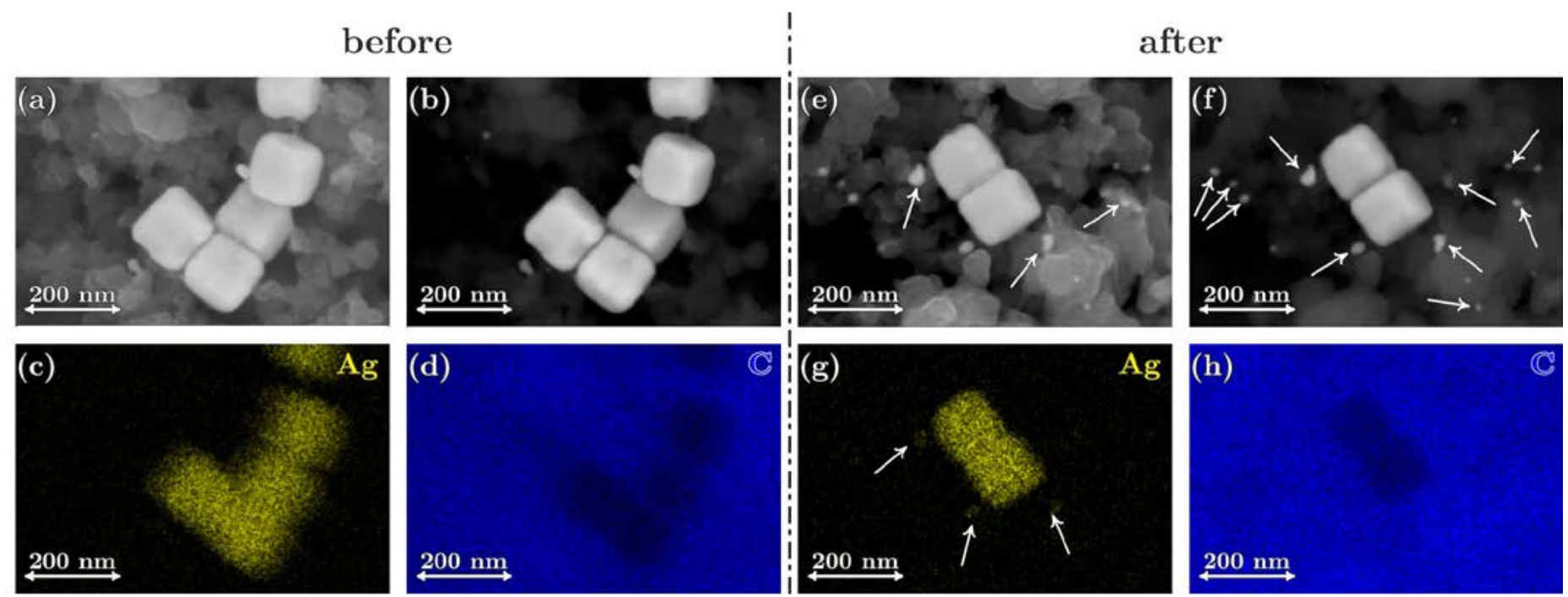

Fig. 2. Ag NCs drop-cast on a GDE, as observed before and after applying the electrochemical treatment shown in Fig. 1, in a $\mathrm{CO}_{2}$-saturated $2.0 \mathrm{~mol} \mathrm{dm}^{-3} \mathrm{KHCO}_{3}$ solution. Panels (a) and (e) show the secondary electron, (b) and (f) the back-scattered electron images of the NCs, with a side length of $\sim 100 \mathrm{~nm}$. Elemental composition maps, recorded by EDX, are shown in panels (c) and (g) for silver and in panels (d) and (h) for carbon. The arrows point to smaller Ag particles, formed by the degradation of the NCs during the potential-induced activation. 
binding strength between the Ag NCs and their PVP coating. [14] The method can be called operando, since it can directly be realized within an electrochemical cell, rendering the use of other (solvent ${ }^{[11]}$ or thermal annealing-based ${ }^{[12,13]}$ ) capping agent removal techniques unnecessary.

In order to apply operando activation, only a single 'breakin' electrolysis cycle (at suitably negative potentials) is required to gain a catalyst that can later work stably and highly active, even at less reductive potentials. The increase of activity is, as seen in Fig. 1, very significant, and following operando activation the catalyst does not lose its activity for hours of electrolyses.

The method has only one, minor flaw: that is, as seen in Fig. 2, during the initial activation step the Ag NCs tend to degrade. As a result, some newly formed, small Ag particles appear on the catalyst surface. These, however, seem not to disturb the electrocatalysis process, and when the electrolysis is continued at milder potentials, degradation stops and no such particles will further be formed.

(a)

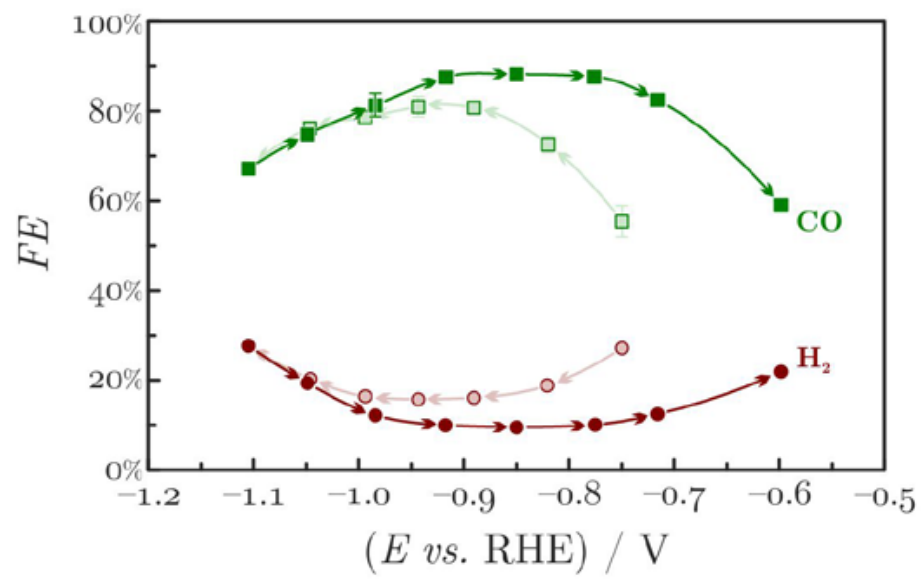

The degradation effects described above can be sufficiently overcome if we make sure that during the 'break-in' cycle only lower currents (creating less mechanical strain) flow through the catalyst. This can be achieved by supplying less reactants to the surface; e.g. by lowering the concentration of the $\mathrm{KHCO}_{3}$ electrolyte from 2 to $0.5 \mathrm{~mol} \mathrm{dm}^{-3}$. By conducting electrolyses in such a system, we observe a hysteresis (Fig. 3) that is similar to the one seen in the previous case, although the measured partial currents (both for $\mathrm{CO}$ and for $\mathrm{H}_{2}$ ) are significantly lower. Yet, this does not seem change the PVP-to-metal binding strength and the value of the cathodic potential that has to be reached in order to break these bonds. Thus the activity increases observed in Fig. 3 compare well with those seen in Fig. 1, while significantly less degradation is observed (compare Figs 4 and 2).

\section{Conclusion}

Silver nanoparticles with well-defined shapes can be fabricated by a variety of synthesis methods, and the thus prepared particles can potentially be used as efficient catalysts in $\mathrm{CO}_{2}$

Fig. 3. Potentiostatic electrolyses were carried out using PVP-coated Ag NCs dropcast on a GDE, used as electrocatalysts of $\mathrm{CO}_{2}$-reduction in a $\mathrm{CO}_{2}$-saturated $0.5 \mathrm{~mol} \mathrm{dm}^{-3} \mathrm{KHCO}_{3}$ solution. Faradaic efficiencies (a) and partial current densities (b) of $\mathrm{CO}$ (green) and $\mathrm{H}_{2}$ (red) are shown as a function of the IR-drop corrected electrode potential. Data (dots) were recorded by gas chromatography; trends (curves) were created by spline interpolation. Arrows show the direction of the potential excursion.
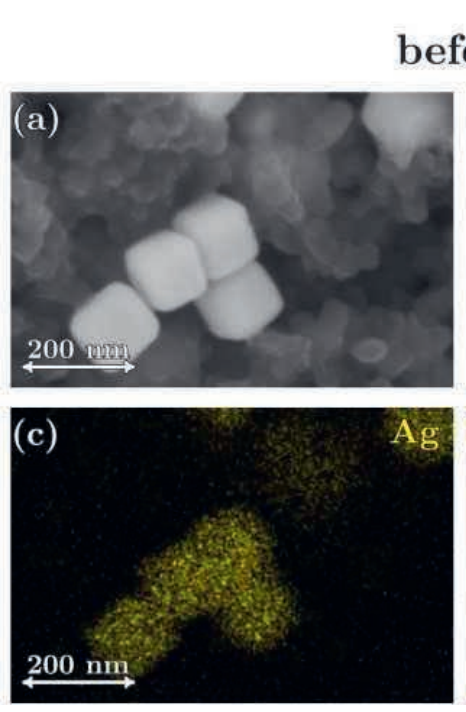
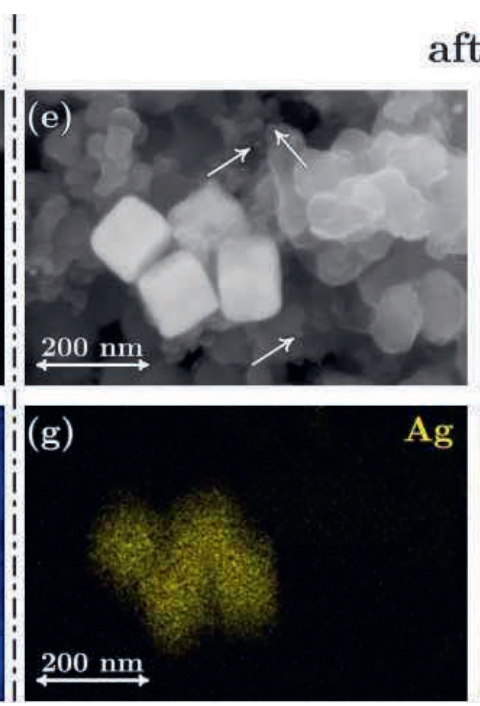

after
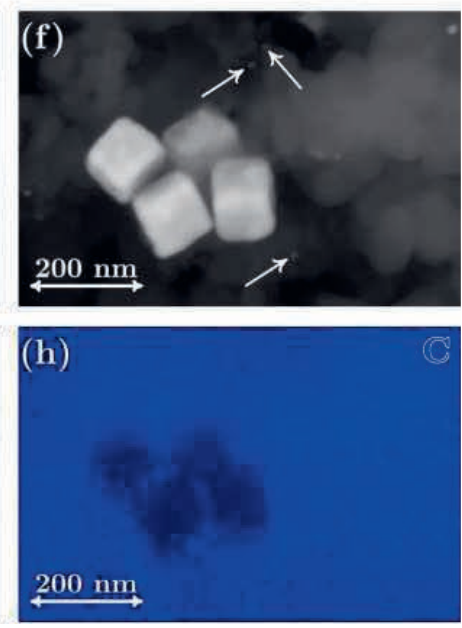

Fig. 4. Ag NCs drop-cast on a GDE, as observed before and after applying the electrochemical treatment shown in Fig. 3, in a $\mathrm{CO}_{2}$-saturated $0.5 \mathrm{~mol} \mathrm{dm}^{-3} \mathrm{KHCO}_{3}$ solution. Panels (a) and (e) show the secondary electron, (b) and (f) the back-scattered electron images of the NCs, with a side length of $\sim 100 \mathrm{~nm}$. Elemental composition maps, recorded by EDX, are shown in panels (c) and (g) for silver and in panels (d) and (h) for carbon. The arrows point to smaller Ag particles, formed by the degradation of the NCs during the potential-induced activation. 
electroreduction. It is a major problem of catalyst design, however, that PVP - a capping agent used for the shape control of the catalyst particles - can remain adsorbed on the surface of the nanostructures, significantly decreasing the catalytic activity. Although some methods (solvent or thermal annealing based ones) are available for PVP removal, these can potentially damage the catalyst by exhibiting it to contaminations or to thermal shock.

In this short communication we described an alternative, potential-induced activation method that can be used to effectively remove PVP from the surface of Ag nanocubes. The method works operando in the electrochemical cell, and requires that before use, the working electrode is polarized to harsh negative potentials. By applying a single 'break-in' cycle, we gain a catalyst that shows higher activity and good stability during subsequent normal operation at mild (not so negative) electrode potentials. The described activation method, as was studied by pre- and postelectrolysis SEM imaging, causes only little degradation to the catalyst surface, and the method can be fine-tuned by selecting proper electrolyte compositions.

\section{Acknowledgements}

P. B. acknowledges financial support by NCCR Catalysis and from the Swiss National Foundation (grant 200020-172507). S. V. acknowledges support from the National Research, Development and Innovation Office of Hungary (NKFIH grant FK135375). M. de J. G.-V. acknowledges the financial support by the Swiss Government Excellence Scholarships for Foreign Scholars (ESKAS). H. H. acknowledges the financial support by the Chinese Scholarship Council (CSC).

Received: January 21, 2021

[1] D. R. Feldman, W. D. Collins, P. J. Gero, M. S. Torn, E. J. Mlawer, T. R. Shippert, Nature 2015, 519, 339, https://doi.org/10.1038/nature14240

[2] E. Royer, Compt. Rend. Hebd. Séances Acad. Sci. 1870, 70, 731.

[3] H.-R. M. Jhong, S. Ma, P. J. A. Kenis, Curr. Opin. Chem. Eng. 2013, 2, 191, https://doi.org/10.1016/j.coche.2013.03.005
[4] F. Yu, P. Wei, Y. Yang, Y. Chen, L. Guo, Z. Peng, Nano Mater. Sci. 2019, 1 60, https://doi.org/10.1016/j.nanoms.2019.03.006

[5] D. Sun, X. Xu, Y. Qin, S. P. Jiang, Z. Shao, ChemSusChem 2019, 13, 39 https://doi.org/10.1002/cssc.201902061

[6] S. H. Im, Y. T. Lee, B. Wiley, Y. Xia, Angew. Chem. 2005, 117, 2192 , https://doi.org/10.1002/anie.200462208

[7] J. Zhang, Q. Wang, X. Zhang, J. Wang, M. Guo, B. J. Wiley, C. Li, C. Hu, Inorg. Chem. Front. 2016, 3, 547, https://doi.org/10.1039/C5QI00256G

[8] K. M. Koczkur, S. Mourdikoudis, L. Polavarapu, S. E. Skrabalak, Dalton Trans. 2015, 44, 17883, https://doi.org/10.1039/C5DT02964C

[9] Y. Hou, N. Kovács, H. Xu, C. Sun, R. Erni, M. d. J. Gálvez-Vázquez, A. Rieder, H. Hu, Y. Kong, M. Liu, B. J. Wiley, S. Vesztergom, P. Broekmann, J. Catal. 2020, 394, 58, https://doi.org/10.1016/j.jcat.2020.12.006

[10] H. Hu, M. Liu, Y. Kong, N. Mysuru, C. Sun, M. d. J. Gálvez-Vázquez, U. Müller, R. Erni, V. Grozovski, Y. Hou, P. Broekmann, ACS Catal. 2020, 10, 8503, https://doi.org/10.1021/acscatal.0c02026

[11] N. Naresh, F. G. S. Wasim, B. P. Ladewig, M. Neergat, J. Mater. Chem. A 2013, 1, 8553, https://doi.org/10.1039/C3TA11183K

[12] I. Puspitasari, E. Skupien, F. Kapteijn, P. Kooyman, Catalysts 2016, 6, 179, https://doi.org/10.3390/catal6110179

[13] Z. Niu, Y. Li, Chem. Mater. 2014, 26, 72, https://doi.org/10.1021/cm4022479

[14] J. R. Pankhurst, P. Iyengar, A. Loiudice, M. Mensi, R. Buonsanti, Chem. Sci. 2020, 11, 9296, https://doi.org/10.1039/D0SC03061A

[15] S. E. Skrabalak, L. Au, X. Li, Y. Xia, Nat. Protoc. 2007, 2, 2182, https://doi.org/10.1038/nprot.2007.326

[16] A. V. Rudnev, in 'Encyclopedia of Interfacial Chemistry', Ed.: K. Wandelt, Elsevier, Amsterdam, 2018, pp. 321-325.

\section{License and Terms}

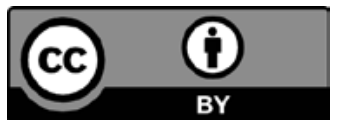

This is an Open Access article under the terms of the Creative Commons Attribution License CC BY 4.0. The material may not be used for commercial purposes.

The license is subject to the CHIMIA terms and conditions: (http:// chimia.ch/component/sppagebuilder/?view=page \&id=12).

The definitive version of this article is the electronic one that can be found at https://doi.org/10.2533/chimia.2021.163 